\title{
Cuidado compartilhado: negociações entre familias e profissionais em uma creche
}

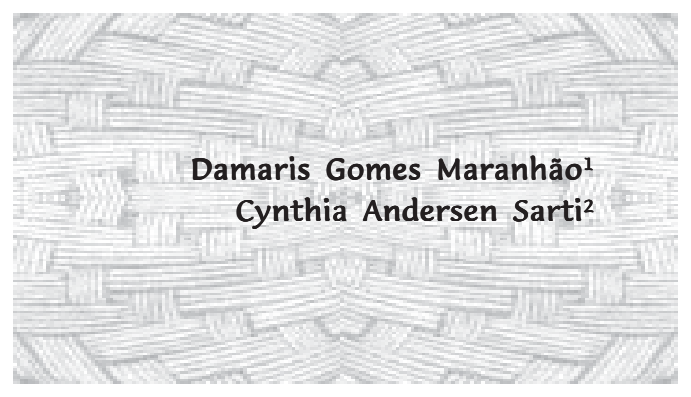

MARANHÃO, D.G.; SARTI, C.A. Shared care: negotiations between families and professionals in a child day care center. Interface - Comunic., Saúde, Educ., v.11, n.22, p.257-70, mai/ago 2007.

Based on a case study of a qualitative nature, this text analyzes the relationship between families and professionals in a child day care center in the process of sharing care during early childhood, using the techniques of observation, interviews and document analysis. The research studied the families and the professionals of a government-run day care center in the city of São Paulo. The conflicts between these social actors became evident, mainly, with regard to care related to feeding and hygiene. The task of sharing care demands from these professionals not only technical preparation, but training in listening to children and their families while taking their uniqueness into account, a requirement that can lead to reflections on the type of care that is most appropriate for the specificity of the group in question, considering the characteristics of locality in its historical and social context.

KEYWORDS: Child rearing. Child day care centers. Child care. Pediatric nursing. Family.

Com base em um estudo de caso, de natureza qualitativa, analisa-se a relação entre família e profissionais de creche no processo de compartilhar cuidados na primeira infância, utilizando técnicas de observação, entrevistas $e$ análise de documentos. Os sujeitos da pesquisa foram os familiares e os profissionais de uma creche pública na cidade de São Paulo. Os conflitos entre esses atores sociais evidenciam-se, sobretudo, nos cuidados com a alimentação e a higiene. Além do preparo técnico, a tarefa de compartilhar cuidados demanda, dos profissionais a formação no sentido da disposição para escutar as crianças e suas famílias em sua alteridade, exigência esta que abre a possibilidade de um espaço de reflexão sobre o cuidado mais adequado para a especificidade do grupo em questão, considerando as características da localidade, em seu contexto histórico e social.

PALAVRAS-CHAVE: Educação infantil. Creches. Cuidado da criança. Enfermagem Pediátrica. Família.

\footnotetext{
*Artigo elaborado a partir de Maranhão, 2005.

${ }^{1}$ Enfermeira; doutora em Ciências; professora, Faculdade de Enfermagem, Universidade Santo Amaro. São Paulo, SP. $<$ damaranhao@uol.com.br>.

${ }^{2}$ Antropóloga; doutora em Antropologia Social; professora, departamentos de Medicina Preventiva e Ciências Sociais, Universidade Federal de São Paulo (Unifesp); diretora acadêmica, Unifesp, campus de Guarulhos. São Paulo, SP. $<$ csarti@unifesp.br>.
}

\footnotetext{
${ }^{1}$ Rua Diogo Rodrigues Marques, 56 


\section{Apresentação}

O cuidado cotidiano da criança, base da promoção de sua saúde, inclui atividades que integram igualmente sua educação: acolher, alimentar, limpar, confortar, proteger, consolar e prover ambiente lúdico e interações, que lhe propiciam situações de aprendizagem sobre si mesma, o outro e a cultura onde está inserida. Os cuidados infantis implicam interação constante entre adultos e crianças, durante o processo de ensinoaprendizagem de regras sociais e práticas culturais de atendimento das necessidades humanas básicas. Assim, cuidar é o elo que integra saúde e educação infantil (Maranhão, 2000 a).

Cuidar da criança é compreendê-la em sua singularidade como ser que está em contínuo processo de crescimento e desenvolvimento, assim como é ajudá-la e ensiná-la a identificar $e$ atender suas necessidades em cada fase e situação, possibilitando que constitua sua identidade, adquira gradativa autonomia e se socialize (Veríssimo, 2003; Maranhão, 2000 a).

A dependência do recém-nascido, na espécie humana, aliada a sua capacidade de expressar as necessidades básicas pelo choro, mímica facial $e$ outros movimentos corporais, desperta no adulto emoções e atitudes de cuidado, ao mesmo tempo em que possibilita a interação necessária entre ele e aquele que cuida, humanizando-o.

Nesse processo, a criança vai se constituindo como pessoa separada da mãe e definindo suas semelhanças e diferenças em relação a seu meio. As expressões e os gestos daquele que cuida e interage com ela são seu primeiro espelho. As reações da mãe ou outro cuidador ao seu corpo e as suas manifestações informam-na sobre quem ela é e a respeito do meio cultural onde vive (Wallon, 1995).

A construção da consciência corporal, imagem das representações que a criança aprende com o outro, é moldada pelas condições concretas de vida, pela linguagem, costumes, crenças e conhecimento próprio de cada época. Esta "noção de um corpo próprio", por sua vez, será permanentemente integrada ao desenvolvimento da personalidade frente ao outro, definindo suas relações com o meio (Wallon, 1995).

Ao longo dos tempos, os grupos humanos têm desenvolvido relações, conhecimentos e tecnologias com a finalidade de cuidar e educar os seus membros mais jovens, assim como manter a saúde dos indivíduos e do grupo.

As mudanças sociais decorrentes, entre outros aspectos, do planejamento dos nascimentos e da inserção da mulher no mercado de trabalho resultaram na organização de outras formas de atender e compartilhar os cuidados cotidianos das crianças. Uma delas é a crescente busca de creche, instituição esta que surgiu para assistir as famílias mais pobres, mas que hoje, gradativamente, constitui espaço especializado no cuidado e na educação infantil.

Compete à família escolher a creche onde a criança irá receber, complementarmente, educação e cuidados. A insuficiência de vagas em creches públicas frente à demanda ou o elevado custo das creches particulares, na maioria das vezes, não permite uma escolha com base em 
princípios, valores e critérios da família. Esta impossibilidade pode determinar uma relação assimétrica entre usuários e instituição, conforme a formulação de Sarti (1998).

Os eventuais conflitos entre profissionais e família, no que se refere ao cuidado e à educação infantil, podem afetar a criança não apenas do ponto de vista do seu processo de aprendizagem e desenvolvimento global, mas também de sua saúde (Maranhão, 2005).

Evidentemente, cuidados corporais fazem parte dos cuidados com a saúde; no entanto, para além dos critérios referenciados pela biomedicina, a percepção do corpo e sua classificação como "normal", "patológico" ou "deficiente", "limpo" ou "sujo", são orientadas por uma ordem de significações culturais que correspondem à visão de mundo e à organização social do grupo do qual o indivíduo faz parte (Douglas, 1966). Assim, saúde e doença são fenômenos híbridos, ao articularem dimensões biológicas, psíquicas e socioculturais, como tem apontado extensa literatura (Sarti, 2001; Canguillem, 2000; Maranhão, 2000 b; Berlinguer, 1998; Ferreira, 1994; Helman, 1994; Douglas, 1966).

As famílias têm percepções e avaliações dos problemas de saúde das crianças com base em seus próprios modelos explicativos de doenças e sua terapêutica (Loyola, 1984). Determinada prática de saúde, originada $e$ valorizada no meio familiar, pode ser considerada inadequada na creche. Este descompasso constitui o eixo central em torno do qual se desenrolam conflitos na relação entre famílias e profissionais de creche, cada um buscando afirmar seu próprio ponto de vista.

A adesão aos valores da instituição, considerada positiva na perspectiva dos profissionais, pode não o ser, necessariamente, para a família. Para esta $e$, em conseqüência, para a criança, pode implicar um enfrentamento com seus valores e costumes, difícil de lidar.

Algumas famílias podem resistir, ainda que não deliberadamente, mantendo suas práticas, numa tentativa de preservar sua identidade social e cultural. Tal procedimento pode ser analisado tanto como um problema que diz respeito à subordinação de classes, uma vez que profissionais e usuários dos serviços podem pertencer a estratos econômicos diferenciados da sociedade (Boltanski, 1984), quanto pelas diferenças de valores, crenças e conhecimentos sobre o que seja um bom cuidado na infância. Busca-se, aqui, situar essa discussão tanto no plano social quanto no cultural.

O objetivo deste trabalho, com base em um estudo de caso, foi analisar a relação entre famílias de crianças usuárias de uma creche e profissionais da instituição no processo de compartilhar cuidados na primeira infância. Esta relação - assimétrica - é permeada por expectativas mútuas, cuja intensidade propicia a emergência de conflitos, tensões e possibilidades que precisam ser constantemente trabalhados, para promover ações conjuntas de cuidado infantil.

\section{Metodologia}

Dado o objeto do estudo - a análise de relações no âmbito de uma creche -, foi utilizada a metodologia qualitativa, mais especificamente, o método de 
estudo de caso (Becker, 1999). Recorreu-se a técnicas etnográficas de coleta de dados: análise das diretrizes básicas expressas nos documentos da instituição, observação participante do cotidiano da creche, e entrevistas abertas (com roteiro prévio) com dez profissionais, 13 familiares (pai ou mãe) e oito crianças.

O trabalho de campo foi desenvolvido entre novembro de 2001 e janeiro de 2003, em uma creche pública situada na região sul do município de São Paulo, classificada na quarta posição relativa ao Índice de Desenvolvimento Humano (IDH), comparada às demais regiões da cidade, embora a maior parte das famílias resida em subprefeituras com menor IDH. Para situar o local de onde falavam os sujeitos, foi construído um "esqueleto" da instituição e seus usuários, apoiado em dados quantitativos, constituindo o que Malinowski (1980) nomeou "anatomia do grupo". Depois, analisaram-se os fatos cotidianos observados, que, na linguagem do mesmo autor, são "a carne e o sangue", as expressões e falas "dos nativos" que constituem o "espírito" do grupo pesquisado, contemplando as perspectivas dos profissionais, das famílias e das crianças (Maranhão, 2005).

A análise articulou as diferentes falas coletadas nas entrevistas e os dados de observação participante e documental, buscando apreender o ponto de vista dos sujeitos investigados sobre a relação família-profissional no processo de compartilhar cuidados infantis. Tomando-se por base a triangulação dos dados, foram construídos quatro eixos temáticos de análise: a construção da parceria entre família e creche; o cuidado compartilhado entre ambas e a criança; a relação entre creche e família, vista na perspectiva da criança; e, finalmente, a complementaridade necessária entre a creche e a família para o cuidado adequado da criança.

Este artigo apresenta os resultados relativos ao segundo tema, focalizando-o com base nos cuidados com a alimentação $e$ a higiene, por constituírem eixos significativos em torno dos quais se evidenciaram conflitos entre família e profissionais, implicando a necessidade de permanentes negociações.

O projeto de pesquisa foi aprovado pelo Comitê de Ética em Pesquisa da Unifesp (processo $n^{\circ} 0177 / 02$ ), cumprindo todas as exigências da Lei 196 de 1996, do Ministério da Saúde, sobre pesquisas envolvendo seres humanos. O consentimento foi dado pelos adultos entrevistados e pelos familiares responsáveis pelas crianças (pai ou mãe). Os nomes apresentados são fictícios, para garantir o sigilo dos mesmos.

\section{Resultados e discussão}

A alimentação: eu ia mudando, eles iam mudando também...

Um aspecto do cuidado que preocupa tanto as mães quanto os educadores infantis é a transição dos hábitos alimentares do âmbito doméstico para o da creche, sobretudo diante da rejeição do alimento oferecido na instituição, interpretada como uma forma de linguagem da criança que expressa algum nível de recusa. Vários autores afirmam que a recusa do alimento pela criança pode desencadear na mãe, ou outra pessoa 
que exerce a função materna, um sentimento de culpa e de rejeição dos seus cuidados, assim como foi observado no comportamento e na fala dos sujeitos desta pesquisa (Ferreira, 2006; Nakano, 2003; Brazelton, 1990).

A alimentação, como qualquer ocorrência corporal, envolve aspectos biológicos relacionados à sobrevivência orgânica, altamente intrincados com o psiquismo e as práticas culturais. Para o bebê humano, as experiências orais, vivenciadas no ato de alimentar, são o primeiro elo com o ambiente (Vygotsky \& Luria, 1996).

No processo de desenvolvimento do bebê, o alimento que entra pela boca e sacia sua fome informa-o sobre o que é interno e externo, ajudando-o a construir, gradativamente, a percepção de ter um corpo separado de sua mãe, processo este que será a base de sua identidade (Wallon, 1995).

Prover alimento é a primeira função materna. Durante a gestação, dá-se pela simbiose fisiológica do feto com sua mãe e, após o nascimento, pela amamentação, função carregada de afetividade (Ferreira, 2006; Nakano, 2003; Brazelton, 1990). Por isso, compartilhar essa função é um desafio às mães, que a concebem como sua por excelência, constitutiva de sua identidade, e também aos educadores, sobretudo quando cuidam de lactentes em aleitamento exclusivo, tendo que os consolar entre uma mamada e outra, enquanto a mãe não chega ou quando ela vai embora.

$$
\begin{aligned}
& \text { (...) quando ela entrou, ela só mamava, só tomava leite no peito. E aqui } \\
& \text { ela tomava leite no copinho, nunca na mamadeira. Aí, depois, ela } \\
& \text { começou a comer papinha que davam pra ela, tudo direitinho. Eu ia } \\
& \text { mudando, eles iam mudando também ... (Mãe de Licia, um ano e meio) }
\end{aligned}
$$

Há vários acertos entre as mães e os educadores, desde o tipo de alimento, a forma de oferecê-lo, o cardápio que vai mudando, conforme a criança cresce e gradativamente torna-se independente. Assim, não são apenas informações objetivas que se compartilham, mas também as subjetivas. No processo de desmame, geralmente associado com a entrada do lactente na creche, a mãe pode se sentir "perdida", à medida que começa a perceber que o filho pode sobreviver sem ela. Essa experiência de perda, vivida pela mãe, é uma das dimensões a serem trabalhadas na adaptação da criança à creche.

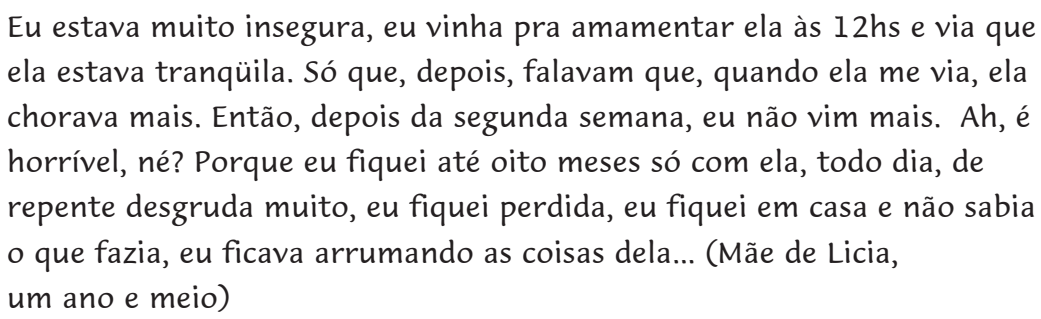

Licia entrou na creche com oito meses, idade em que já poderia estar recebendo outros alimentos, complementados pelo leite materno de manhã $e$ à noite. Assim, os educadores "negociaram" com sua mãe a substituição da mamada do meio dia pelo almoço. Tratou-se de "negociação", pois a oferta de qualquer alimento à criança, pela mãe, tem sentido afetivo. 
Eu fico pra fazer ela comer porque eu acho que ela não vai comer. Depois que ela come, eu vou embora. Todo dia ainda ela chora. Eu entro, vou tomar café com ela, fico lá fazendo companhia pra ela, depois, eu vou à sala, brinco um pouco. Ela já percebe que eu vou embora e começa a chorar, aí eu tenho que entregar ela pra algum educador e ir embora (Mãe de Licia, um ano e meio).

Com o tempo, a mãe nota que a convivência coletiva tem vantagens no sentido de ampliar o repertório alimentar, ajudando, também, a criança a aprender a servir-se e provar alimentos que, em casa, não eram oferecidos ou aceitos. Às vezes, a criança come determinados alimentos na creche $e$ não os aceita em casa, dizem algumas mães. Ela se comporta de maneira diferente, porque percebe que são lugares distintos e pessoas com papéis sociais diferentes.

E agora ela come, eu não sabia, mas ela gosta muito de legumes, adora. Eu achava que não, porque normalmente as crianças não gostam, mas ela adora. Agora, a gente procura dar mais verduras e legumes pra ela. Ela come melhor também se estiver em companhia de outras crianças, porque sozinha ela não gosta de comer. Eu acho que aqui ela come bem. (Mãe de Licia, um ano e meio)

Na perspectiva das crianças entrevistadas - entre cinco e seis anos de idade e que já freqüentam a instituição há mais tempo, as vivências em casa e na creche constituem importantes referências. As situações vividas são classificadas como boas ou ruins, de acordo com o que cada local proporciona de prazer ou desprazer.

Eu gosto mais de almoçar na minha casa, porque quando nós não agüenta mais, quando nós não quiser comer mais, nós não come. $\mathrm{Na}$ creche, tem que comer tudo, a professora fala que é para ficar forte. Mas eu não queria ficar só em casa, porque meu avô me dá um prato cheio desse tamanho!! (Karen, seis anos)

Quando o esquema alimentar em casa é muito diferente da creche, é necessário um período de transição, em que se mantêm os hábitos $e$ costumes da criança que, gradativamente, vai se adaptando ao novo cardápio.

O Marcos tem dois anos e entrou este ano na creche. A mãe queria que fosse dada mamadeira pra ele em todas as refeições, porque, segundo ela, não aceitava outros alimentos. Ela trazia o leite e o engrossante. Um dia, ele aceitou o almoço e eu pedi para as meninas devolverem o leite. A mãe ficou muito brava porque não tínhamos dado a mamadeira na hora do almoço. Nossa, ela rodou a baiana, chegou muito nervosa, xingando todo mundo. Como a gente podia deixar o filho dela passando fome, não sei o quê! "Não, olha lá - eu falei - ele está comendo o pão, tomando leite, não tem necessidade de mamadeira. Ele deixou de tomar mamadeira". Eu 
mostrei a ela que não precisava, porque ele estava se alimentado bem. "Quando ele chegar em casa, você faz a mamadeira e dá. Mas aqui na creche não precisa, ele come comida" Assim, você não faz o que ela quer, mas também não deixa a mãe triste. Na verdade, eu acho que, para a mãe, a mamadeira tem um significado: eu não estou lá, mas se a mamadeira está lá, a mamadeira está no meu lugar. (Técnica de Enfermagem)

Esta técnica de enfermagem compreendeu o significado que a mamadeira tem para esta mãe e ajudou-a a perceber que o filho não é mais um bebê e pode se servir de alimentos mais adequados para sua idade, com autonomia, tentando não deixar a mãe triste.

Superadas as dificuldades iniciais, as famílias elogiam a alimentação da creche, a diversidade do cardápio e a higiene em seu preparo. Não é apenas o reconhecimento dos aspectos nutricionais que estão em jogo, mas também os educativos e emocionais.

Outra coisa que eles adoram, e para a gente é interessante, é alimentação; o Wilson, hoje, ele come de tudo, porque ele aprendeu a comer aqui. (Pai de Wilson, seis anos)

Associados ao afeto, os modos de alimentar a criança são construídos na cultura, sendo influenciados pelo tipo de alimento disponível em cada região, por costumes e valores, inclusive, religiosos. Os profissionais da creche aceitam restrições alimentares, quando prescritas por médicos, o que nem sempre ocorre quando são determinadas por costumes familiares. Uma mãe converteu-se à religião Hare Krishna e solicitou que não dessem carne à sua filha, mas não foi atendida em seu pedido, sob o argumento de que, no contexto coletivo, era difícil evitar que a criança se servisse da carne oferecida no cardápio - o que revela a dificuldade dos profissionais de considerar singularidades e valores próprios dos usuários.

O que tem para comer todos vão comer, se a criança quiser, não vai deixar passar vontade, porque a mãe não quer que coma a carne. Na casa dela não vai dar, mas aqui tem e ela vai comer. (Educadora do Maternal)

Outra família, adventista, solicitou que a criança não comesse carne de porco. Como este alimento não fazia parte do cardápio da creche, não houve problemas no atendimento do pedido.

Quando chegamos aqui, não forçamos, mas deixamos avisadas duas coisas: "Olha, a gente gostaria que toda atividade que tivesse no sábado, e qualquer coisa que tivesse carne de porco não fosse dado à Juliana, não fosse cedido a ela, porque a gente está educando ela nesse princípio, a gente tenta ser coerente. (Pai de Juliana, dois anos)

Do ponto de vista da criança, a creche oferece oportunidades de acesso a valores, hábitos alimentares, cuidados e conhecimentos que podem ser 
diferentes daqueles das famílias, propiciando outras oportunidades de desenvolvimento (Wallon, 1995). Na família, com seus próprios valores, suas crenças e seus hábitos, a criança tem um lugar estrutural de identidade, que a acompanhará permanentemente, fazendo com que seu processo de desenvolvimento envolva lidar com todas essas referências, com os conflitos e ganhos implicados (Sarti, 2004).

A higiene: eu acho que está mais relacionado ao cuidado...

A origem etimológica do termo higiene é derivada do grego hygeinos: o que é são. Entretanto, o senso comum atribui-lhe significado mais restrito: asseio e limpeza. Nos dicionários de língua portuguesa, identifica-se este duplo significado, de ciência que visa à preservação da saúde, à prevenção da doença e ao asseio (Maranhão \& Vico, 2004; Vigarello, 1996). A partir do século XVII, o termo "limpo" começa a adquirir conotações morais, passando a significar também distinção, elegância, ordem (Rodrigues, 1999; Vigarello, 1996).

Desde o fim do século XVIII, o corpo sadio, limpo, válido, os espaços purificados, límpidos, arejados, a distribuição medicamente perfeita dos indivíduos, lugares, leitos, utensílios, o jogo do 'cuidado' e do 'cuidadoso', constituem algumas leis morais essenciais da família. (Foucault, 1979, p.199)

As regras de higiene são construções culturais e revelam mais uma necessidade humana de ordenar forma e função, dar ordem a algo que parece caótico, do que uma técnica com base no conhecimento da transmissibilidade ou causalidade das doenças (Douglas, 1966).

Os profissionais da creche usam-na como sinônimo de limpeza, fazem referências a conflitos em razão da falta de asseio das crianças, freqüentemente atribuída ao descuido da mãe e a sua pobreza material.

\footnotetext{
A mãe, às vezes, cortava um pedaço do lençol, fazia de fralda, e trazia a menina assim. Às vezes, ela não tinha nem um pano, nada, e a criança chegava aqui só de calcinha e ficava toda suja de cocô. Nós procurávamos orientar da melhor forma possível, mas é muito difícil estar orientando esse tipo de mãe. Foram fazer uma visita na casa dela, do lado do tanque tinha um monte de roupa, há mais de duas semanas lá, ia juntando, juntando. Não sei o que ela fazia com aquela roupa, não sei se lavava ou não. Todo dia nós tínhamos que dar banho nela e colocar uma roupa da creche, porque a sua roupa cheirava mal demais. Era uma criança muito bonita, mas muito mal cuidada. Eu ficava chocada e procurava sempre orientar a mãe: "Vamos fazer dessa forma...". (Coordenadora Pedagógica)
}

Cuidar de crianças de diferentes condições sociais implica lidar com costumes diversos e reconhecer as limitações da creche frente aos problemas econômicos e culturais das famílias, associados à precariedade habitacional, às dificuldades de acesso aos serviços de saúde e a bens básicos 
para o bem-estar infantil. Além das limitações que a pobreza coloca para as famílias e educadores, cada família reage e lida à sua maneira com suas condições de vida. Ao tratar dessas diferenças, embora os educadores reconheçam que a falta de condições em casa pode dificultar os cuidados com as crianças, isso não impede que se dêem conotações morais ao fato, fazendo do cuidado infantil um dos eixos de julgamento moral da família.

A mãe estava meio acomodada, ela sabia que, quando a menina chegasse aqui, ia tomar banho, colocar uma roupa limpa nela. A gente pedia para devolver aquela roupa, mas ela não devolvia. Ela foi se acomodando, porque ela via que a creche ajudava demais, né?A mãe chegou num ponto... Parece que eles estavam passando necessidade, ela estava sem marido, estava sempre trocando de marido. Nós achávamos que ela se prostituía. O pessoal comentava, a gente não pode julgar pela roupa das pessoas, mas, às vezes, estava um frio, que a criança chegava com o lábio roxo aqui e a mãe vinha com um shortinho curtinho, mini-blusa, sabe, sempre com roupas extravagantes, e o pessoal comentava que via ela na Alameda (rua próxima à creche com casas e hotéis de prostituição) conversando com os homens, sabe? Era comentário mesmo das mães que a gente ouvia. (Educadora do Jardim)

As famílias são avaliadas pelos educadores tanto pela aparência da criança quanto pela forma como se comportam e se apresentam na creche. Embora tentem compreender as dificuldades enfrentadas pelas mais pobres, comparam e elogiam aquelas que, apesar da pobreza, são limpas e cuidadosas.

Eu conheci vários tipos de famílias. Havia mães que não ligavam muito pra criança, não ligava muito pra roupa da criança. Outras, mesmo sendo muito pobre, tinha cuidado até demais com a criança. A gente fazia entrevista com as mães para saber como é a higiene dela em casa com a criança. Havia uma família que morava num cortiço, com tanque de uso comum, mas que tinha noção de higiene, lavava a roupa dentro de um balde, para não usar o tanque comum, parar manter tudo individual. Era um exemplo! (Educadora do Berçário)

Assim, por meio da observação do corpo da criança, os educadores avaliam $e$ criticam as famílias que consideram negligentes, apesar de um perceptível cuidado no sentido de não parecerem preconceituosas aos olhos da pesquisadora. Essa vigilância decorre da tendência atual, na educação infantil, de rever a visão sobre as famílias pobres como "carentes", "incapazes", "desestruturadas", "negligentes".

Eu acho que está mais relacionado ao cuidado. Eu não gosto de falar assim porque parece que a gente tem preconceito - e eu não tenho preconceito - procuro ser uma pessoa humilde no meu dia-a-dia, procuro chegar ao nível da... (família?) Nós somos todos iguais, mas tem mães sem higiene com a criança, que não separa aquela roupinha de xixi que 
foi dentro da mochila, fica tudo cheirando, não lava a mochila da criança! (Educadora do Jardim)

Os profissionais têm ciência de que o padrão de higiene em um contexto pode ser diferente do de outro, mas, ao mesmo tempo, negam o preconceito e fazem associações que o reafirmam.

Eu sou de Curitiba e lá a gente tenta seguir um padrão de higiene, tomar cuidado para não contaminar. Em casa, a gente sabe que nunca é assim, até mesmo na casa da gente, temos deslizes, né? Como a gente atende famílias de várias rendas, geralmente quem tem um poder aquisitivo baixo, a falta de higiene é o que mais predomina nelas. Por exemplo, a mãe do Edilson melhorou muito a higiene com as crianças, mas não a pessoal. Ah, coitada, porque é casada com aquele velho, né? (Técnica de enfermagem)

A associação que os profissionais fazem da falta de cuidado familiar, particularmente de higiene, com os episódios de adoecimento das crianças, desvia o foco do planejamento dos cuidados na creche. O emprego de precauções-padrão, em lugar de adotar medidas relativas apenas à criança doente, evitaria estigmas vivenciados pelas crianças (Maranhão \& Vico, 2004; Maranhão, 2005).

Às vezes, a gente toma suco no copo e a professora põe durex. Então, tem que anotar, senão passa doença pro outro. Não é todo mundo que vai ficar com durex. É só para aquela pessoa que está doente... Os meninos riem, mas as meninas, não. (Karen, seis anos)

Os cuidados com o corpo também incluem a estética, os adornos e, ainda, os adereços usados pelas famílias para "proteger" a criança, agradecer graças alcançadas, expressando suas crenças e valores, que podem ser estranhos aos educadores, evidenciando um descompasso entre profissionais $e$ famílias, fonte de desentendimentos que leva, mais uma vez, a negociações:

Tem aquelas mães que fazem promessa: "Quando meu filho fizer um ano, eu vou cortar o cabelo dele e levar lá pra Aparecida do Norte”. Só que o filho estava com o cabelo desse tamanho e cheio de lêndea. Aí, um dia, a educadora cortou o cabelo do menino sem falar com a mãe. Estava tentando ajudar: "acho que eu vou cortar o cabelo desse menino, a mãe não deve ter condição de levar pra cortar”. Aí, a mãe chegou aqui e fez o maior carnaval. Ela queria o cabelo do menino porque, quando fizesse um ano, levaria para Aparecida do Norte. E a educadora já tinha jogado o cabelo da criança no lixo. Porque a gente achava que tinha que manter a criança limpa, brilhando, perfumada, com o cabelo cortadinho, porque essa era a nossa função. A mãe coitada, né? Nós tivemos que ir ao lixo procurar o cabelo, para a mãe dele levar. E aí a gente vai aprendendo, eu nunca mais corto o cabelo de ninguém! (Coordenadora Pedagógica) 
As diferenças culturais que permeiam o processo de compartilhar cuidados com as famílias ensinam aos educadores os limites em relação ao que consideram "o melhor para a criança". No julgamento do que consideram o melhor cuidado, perpassam valores religiosos, estéticos, relativos ao gênero, que revelam preconceitos com base em percepções diferentes. Ao adjetivar a mãe como "coitada", desvalorizam sua perspectiva. Algumas famílias fazem valer sua autoridade, como o direito de escolher o que consideram melhor aos filhos. Outras, temendo a rejeição social, acabam mudando sua prática, diante dos argumentos dos profissionais.

Antes de o Leo entrar na creche, eu levei ele na benzedeira, eu achava ele fraquinho, miudinho. A minha vizinha falava - é quebrante, mau-olhado, né? A benzedeira confirmou: "É mau-olhado". Depois de uns três dias, a mesma coisa, ele ficou tristinho, levei ele de novo na benzedeira. "Ele é muito pegado de mau-olhado, eu vou fazer um negocinho para que ele não pegue mais". Aí não pegou mesmo. Aí a creche me perguntou o que era aquilo [o amuleto]. Falei que... eu pensei..., será que a creche não gosta? Aí eu tirei. Eu pensei que a creche não gostava. Ninguém falou nada. Me perguntaram, eu achei que a creche não gostava. Aí eu tirei. Eu fiquei assim... será que a creche não gosta? Aí eu tirei. (...) Levou uns três dias, fiquei com medo dele puxar [o alfinete]. Aí eu tirei, ele era bebezinho. Aí eu fiquei com medo, depois ele puxou e eu tirei. Eu tenho mais medo dele furar. Ele já estava crescidinho, eu fiquei com medo dele puxar, furar, daí eu tirei. Ele era muito bebezinho, eu fiquei com medo. (Mãe do Leo, três anos)

A interpretação feita deste caso é a de que a mãe buscou o que considerava uma proteção espiritual para o corpo do filho, que poderia tornar-se fraco pelos maus-olhados. Essa proteção era feita por um amuleto, adereço vermelho preso com alfinete à roupa da criança. Ao tornar-se usuária da creche, percebeu que correspondia a uma prática considerada inadequada, implicando rejeição de seu filho. Qual o maior medo? Da doença ou do estigma? Da rejeição? Deslocou a proteção para formas culturalmente aceitas, como agasalhá-lo, amamentá-lo, tornar-se vigilante de sua saúde.

Tudo que ela não podia fazer durante o dia, ela queria fazer na hora da saída: trocar, colocar cinco blusas, quatro calças, amamentar! Ela achava que ele não tinha pegado peso, porque ele só vivia doente. Ela queria saber se ele tinha ficado bem, se estava com febre, até perceber que ele conseguia ficar bem na creche. Levou o maior tempo. Quer dizer, ela era muito boazinha com todo mundo, mas tinha uma insegurança! Tudo que você falava ela concordava, mas você via que ela morria de medo, tudo dava desespero: "Por que ele estava doente? Ele está com febre de novo?" Ela ligava do serviço pra saber se ele teve febre, o que ele comeu. Era bem assim (...) Você está ali do lado e aí ela chega na educadora e confirma aquilo que você falou. E é então na confirmação das coisas que ela vai criando vínculo com a equipe. Não só com a enfermagem. Aí ela percebia 
que você realmente estava participando do que estava acontecendo com o filho dela. (Técnica de Enfermagem)

Duas dimensões subjazem aos conflitos que incidem no processo de compartilhar cuidados de alimentação: uma diz respeito à afetividade implícita no ato de alimentar, que exige sensibilidade para identificar o sentido desse ato para a família, ajudando-a a compreender que a construção da autonomia, pela criança, passa pelo desenvolvimento da capacidade de ela prover seu próprio alimento. A outra se refere às diferenças culturais, regionais ou religiosas que, se não puderem ser acolhidas e gradativamente incorporadas, pelo menos, precisam ser reconhecidas.

Nos conflitos em torno dos cuidados de higiene, percebe-se claramente a postura disciplinar da equipe profissional, associada à moralização dos costumes. Todavia, há casos evidentes de negligência que ferem o direito das crianças e requerem um trabalho com a família, no sentido de refletir com ela sobre o significado do cuidado no processo de construção da identidade. Lidar com a negligência do adulto em relação à criança, classificada como "maus-tratos", é uma tarefa complexa, sutil e delicada, por dizer respeito ao olhar sobre o outro. Pode revelar preconceitos de várias ordens. O que é visto como "negligência" pode expressar uma forma diferente de cuidar.

\section{Considerações finais}

Os conflitos são inerentes às relações entre profissionais e familiares das crianças usuárias de creches, evidenciando-se no processo de compartilhar cuidados, sobretudo, relativos a alimentação e higiene.

Compartilhar cuidados infantis demanda dos profissionais preparo $e$ disposição para escutar crianças, pais, avós, comunidade, em sua alteridade, constituindo um fórum de reflexão sobre o que seja o melhor cuidado e a melhor educação para esse grupo específico, em seu contexto histórico, social e cultural.

Nessa tarefa, a concepção de participação dos pais é a de co-construtor do projeto de educação e cuidado infantil, pela definição conjunta de concepções, normas e regras. Isto implica uma atitude de profissionalismo, considerando o arsenal dos saberes acumulados sobre desenvolvimento, educação e cuidado infantil e sobre os padrões do que seja uma boa creche, bem como conhecê-los, problematizá-los, refletir sobre sua aplicabilidade em um contexto específico. Implica, ainda, a abertura aos conhecimentos "não científicos", que iluminam as práticas familiares, constituindo, também, formas de saber.

Essa pesquisa, embora tenha tido como foco o processo de compartilhar cuidados das crianças no contexto de uma creche, pode contribuir para a reflexão de profissionais que atuam nos programas de saúde da família e nas unidades básicas de saúde, no sentido de considerarem a complexidade e dinâmica das relações que se estabelecem em torno do cuidado infantil. 


\section{Referências}

BECKER, H.S. Métodos e pesquisas em ciências sociais. 4.ed. São Paulo: Hucitec, 1999.

BERLINGER, G. A doença. São Paulo: Hucitec, 1998.

BOLTANSKI, L. As classes sociais e o corpo. 2.ed. Rio de Janeiro: Graal, 1984.

BRAZELTON, T.B. Alimentação: prazer ou campo de batalha. In. Paulo: Martins Fontes, 1990. p.85-97. . (Org.). Ouvindo uma criança. São

CANGUILHEM, G. O normal e o patológico. 5.ed. Rio de Janeiro: Forense Universitária, 2000.

DOUGLAS, M. Pureza e perigo. São Paulo: Perspectiva, 1966. (Debates, 120)

FERREIRA, A.O. Hora da chantagem: viver mente e cérebro: revista de psicologia, psicanálise, neurociências e conhecimento. Sci. Am., n.164, p.44-7, 2006.

FERREIRA, J. O corpo sígnico. In: ALVES, P.C.; MINAYO, M.C.S. (Orgs.). Saúde e doença: um olhar antropológico. Rio de Janeiro: Fiocruz, 1994. p.101-12.

FOUCAULT, M. Microfísica do poder. 16.ed. Rio de Janeiro: Graal, 1979.

HELMAN, C.G. Cultura, saúde e doença. 2.ed. Porto Alegre: Artes Médicas, 1994.

LOYOLA, M.A. Médicos e curandeiros: conflito social e saúde. São Paulo: Difel, 1984.

MALINOWSKI, B. Objeto, método e alcance desta pesquisa. In: GUIMARÃES, A.Z. (Org.). Desvendando máscaras sociais. 2.ed. Rio de Janeiro: Francisco Alves, 1980. p.39-61.

MARANHÃO, D.G. O cuidado como elo entre a saúde e a educação. Cad. Pesqui., n.111, p.115-33, 2000a.

. O processo saúde-doença e os cuidados com a saúde na perspectiva dos educadores infantis. Cad. Saúde Pública, n.16, p.1143-8, 2000b.

. O cuidado compartilhado: relações entre famílias e profissionais de uma creche. 2005. Tese (Doutorado) - Pós-Graduação em Enfermagem, Universidade Federal de São Paulo, São Paulo.

MARANHÃO, D.G.; VICO, E.S.R. Higiene e precauções padrões em creche e pré-escola: contribuindo para um ambiente saudável. In: SANTOS L.E.S. (Org.). Creche e pré-escola: uma abordagem de saúde. Porto Alegre: Artes Médicas, 2004. p.131-48.

NAKANO, A.M.S. As vivências da amamentação para um grupo de mulheres: nos limites de ser "o corpo para o filho" e de ser "o corpo para si". Cad. Saúde Pública, v.19, suppl.2, p.355-63, 2003.

RODRIGUES, J.C. O corpo na história. Rio de Janeiro: Fiocruz, 1999.

SARTI, C.A. A assimetria no atendimento à saúde: quem é o "necessitado"? In: REUNIÃO ANUAL DA ASSOCIAÇÃO NACIONAL DE PESQUISA E PÓS-GRADUAÇÃO EM CIÊNCIAS SOCIAIS, 22., 1998, Caxambu. Programas e Resumos... Caxambu, 1998. p.109.

. A dor, o indivíduo e a cultura. Saúde Soc.. v.10, n.1, p.3-13, 2001.

. A família como ordem simbólica. Psicol. USP, v.15, n.3, p.11-28, 2004.

VERÍSSIMO, M.D.L.Ó. O cuidado da criança segundo as trabalhadoras de creches. Rev. Latino-Am. Enfermagem, v.11, n.1, p.28-35, 2003.

VIGARELLO, G. O limpo e o sujo: uma história da higiene corporal. São Paulo: Martins Fontes, 1996.

VYGOTSKY, L.S; LURIA, A.R. Estudos sobre a história dos comportamentos: símios, homem primitivo e criança. Porto Alegre: Artes Médicas, 1996.

WALLON, H. As origens do caráter da criança. São Paulo: Nova Alexandria, 1995. 


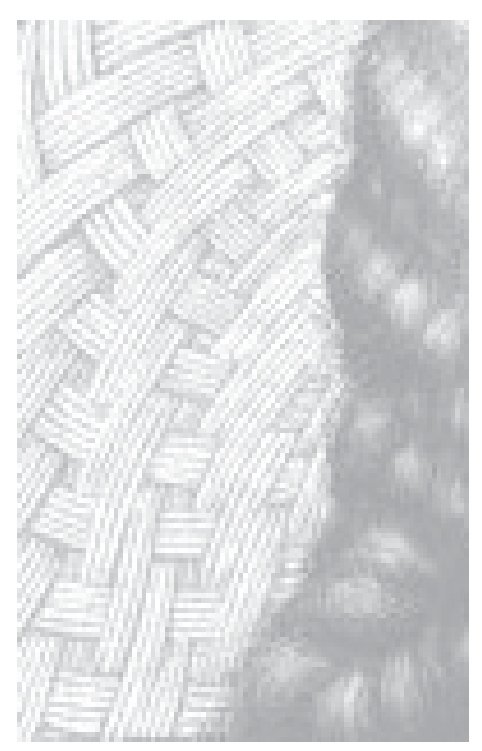

MARANHÃO, D.G.; SARTI, C.A. Cuidado compartido: negociaciones entre familias y profesionales de una guardería. Interface - Comunic., Saúde, Educ., v.11, n.22, p.257-70, mai/ago 2007.

Basado en un estudio de caso, de naturaleza cualitativa, este texto busca analizar la relación entre familia y profesionales de una guardería en el proceso de compartir cuidados en la primera infancia, utilizando técnicas de observación, entrevistas y análisis de documentos. Los sujetos de la investigación fueron las familias y los profesionales de una guardería en la ciudad de São Paulo. Los conflictos entre estos agentes sociales se evidencian, sobre todo, en los cuidados con la alimentación y la higiene. Además de preparación técnica, la tarea de compartir cuidados exige de los profesionales la capacitación en el sentido de la disposición para escuchar a los niños y sus familias en su alteridad. Esta exigencia abre, entonces, la posibilidad de un espacio de reflexión sobre el cuidado adecuado a la especificidad del grupo en cuestión, considerando las características locales, en su contexto histórico y social.

PALABRAS CLAVE: Educación en la primera infancia. Guardería. Cuidado del nino. Enfermería Pediátrica. Familia. 